\title{
State vocational rehabilitation programs and federal disability insurance: an analysis of Virginia's vocational rehabilitation program
}

\author{
David Dean ${ }^{1 \wedge}$, John V Pepper ${ }^{2 *}$, Robert M Schmidt ${ }^{1}$ and Steven Stern ${ }^{2}$
}

\author{
* Correspondence: \\ jvp3m@virginia.edu \\ Deceased \\ ${ }^{2}$ University of Virginia, \\ Charlottesville, VA, USA \\ Full list of author information is \\ available at the end of the article
}

\begin{abstract}
We examine the association between the receipt of vocational rehabilitation (VR) services and Federal Disability Insurance using a unique panel data source on persons who applied for assistance from Virginia's VR program in 2000. Three central findings emerge: first, VR services are associated with lower rates of participation in disability insurance programs-a nearly 2 point drop in SSDI receipt and 1 point drop in SSI receipt. Second, VR service receipt is associated with lower take-up rates of SSDI/SSI. Finally, among VR applicants on SSDI/SSI, those who receive substantive VR services are more likely to be employed.

JEL codes: H51, 113, J24

Keywords: Vocational rehabilitation; Disability insurance
\end{abstract}

\section{Introduction}

As the enrollment and costs of the Social Security Administration's Disability Insurance (SSDI) and Supplemental Security Income (SSI) programs have grown over the past two decades, there has been growing interest in whether vocational rehabilitation (VR) programs might serve to reduce the number of persons receiving federal disability insurance benefits (e.g., Autor and Duggan 2010; Stapleton and Martin 2012). Disability insurance programs provide cash assistance to people with determinable and significant work disabilities. By contrast, the public-sector Vocational Rehabilitation (VR) program, a $\$ 3$ billion federal-state partnership, is designed to provide employment-related assistance to persons with a broad spectrum of disabling conditions. As the nation's primary employment support program for people with disabilities, state VR agencies seem wellpositioned to assist people with disabilities in securing gainful employment rather than receiving SSDI/SSI (Stapleton and Martin 2012). Yet, while found to play an important role in helping persons with disabilities to engage in the labor market (Loprest 2007; Dean et al. 2013a, 2013b and 2013c), very little is known about whether VR services reduce participation in Federal Disability Insurance programs ${ }^{1}$. If VR services improve labor market outcomes of potential SSDI/SSI beneficiaries, some clients may choose to fully participate in the labor market rather than take up SSDI/SSI. Yet, for those with limited abilities or interest, VR programs may instead serve to help clients understand 
Federal Disability Insurance programs and rules, and consequently lead to an increase in take-up (Stapleton and Martin 2012; Dean et al. 2013a).

Using a unique panel data source on all persons who applied for VR services in Virginia in State Fiscal Year (SFY) 2000, we study the relationship between VR service receipt and SSDI/SSI receipt. For each applicant, we observe quarterly SSDI/SSI, employment and earnings data, and VR service receipt data from 1995 to 2010. This rich panel data enable us to provide important insights into the long-run impact of VR services on receipt of Federal Disability Insurance. Given that the labor market impacts of VR services are known to differ by the type of limitation (Dean and Dolan 1991; Baldwin 1999; Dean et al. 1999; Marcotte et al. 2000; Dean et al. 2013a, 2013b and 2013c), we analyze the full population as well as subpopulations of clients with a physical impairment, mental illness, or cognitive impairment ${ }^{2}$. We also examine SSDI and SSI receipt separately: the two groups of recipients have very different characteristics, receive different benefit amounts, and face different earnings incentives. In particular, the non-medical eligibility criteria for SSDI requires a significant work history, SSDI benefits vary with work history, and SSDI benefits are terminated when a recipients earnings exceed some threshold. In contrast, SSI is means-tested and SSI benefits are determined using a fairly standard negative income tax formula with a basic guarantee and 0.50 earnings tax after a small earnings disregard.

After describing the data in Section 2, we proceed in two parts. In Section 3, we consider the association between VR service receipt and participation in SSDI and/or SSI, specifically examining take-up and exits from the Federal Disability Insurance programs. In Section 4, we evaluate the association between VR receipt and labor market outcomes, focusing on clients who received SSDI/SSI prior to applying for VR services.

Finally, in Section 5, we draw conclusions. Three central findings emerge. First, in general, VR services are associated with lower rates of participation in disability insurance programs - a nearly 2 point drop in SSDI receipt and 1 point drop in SSI receipt - but there is substantial variation across impairment groups. Most notably, for the cognitively impaired subgroup, VR services are associated with greater SSDI/SSI receipt. Second, VR receipt is associated with lower rates of entry into SSDI/SSI but also lower rates of exit from the SSDI roles. Finally, among VR applicants on SSDI/SSI, those who receive substantive services are more likely to be employed but, on average, earn less per quarter.

While these results may suggest that VR programs can effectively reduce SSDI/SSI roles for certain subgroups, we caution against drawing this type of causal conclusion from the evidence presented in this paper. Rather, this analysis is largely descriptive, and does not formally address the fundamental methodological problem involved in drawing such inferences from observational data. Specifically, the decision to provide VR services is not likely to be random, or exogenous, with respect to SSDI/SSI receipt. Selection has been found to be a central problem in addressing the impact of job training programs in general (LaLonde 1995; Friedlander et al. 1997 and Imbens and Wooldridge 2009), and VR program in particular (Aakvik, Heckman, and Vytlacil, 2005; Stapleton and Martin 2012 and Dean et al. 2013a, 2013b and 2013c). Hence, the observed associations evaluated in this paper are likely to reflect, in part, unobserved factors such as the severity of disabling limitation and general health status which are likely to be jointly associated with VR service and SSDI/SSI receipt. Likewise, the Social Security Administration's costsharing arrangement with VR agencies for services provided to certain SSDI/SSI beneficiaries further confounds causal inference (see Stapleton and Martin 2012). 


\section{Data}

The data used for this analysis come from three different administrative sources. Our starting point is the administrative records of the Virginia Department for Aging and Rehabilitative Services (DARS) on individuals who applied for VR services for the first time in SFY 2000 (July 1, 1999 - June 30, 2000). We limit the sample to 6,732 first-time applicants between the ages of 21 and 55 at the quarter of application ${ }^{3}$. For each respondent, we observe an indicator for whether they received substantive VR services, which we refer to as "treated" applicants ${ }^{4}$. In addition to observing whether or not the client received VR services, we observe a range of demographic variables as well as indicators for whether the client had a physical (PI), mental (MI), or cognitive impairment $(\mathrm{CI})^{5}$. Variables from the DARS records are measured at the time of a clients most recent application for VR services, and thus do not vary over the estimation time frame. We then merge these DARS records with quarterly administrative records on labor market activity from the Virginia Employment Commission (VEC) ${ }^{6}$ and monthly administrative records of the Social Security Administration (SSA) on Social Security Disability Insurance (SSDI) and Supplemental Security Income (SSI) benefit receipt from 1995 (quarter 2) to 2009 (quarter 4) . $^{7}$ Thus, for each DARS applicant, we observe quarterly employment, earnings, and disability insurance receipt for many years before and after the application quarter in SFY 2000.

\section{Summary statistics}

Table 1 displays the means and standard deviations of the variables for the full sample, for the treatment groups, and for three impairment groups. Of the 6,732 first-time DARS applicants, $61 \%$ are provided VR services. The treatment rate is similar for clients in the PI and MI subsamples but much larger for the CI subsample where just over three-fourths of clients with cognitive impairments are provided with substantial VR services.

For each applicant, we observe indicators of disability insurance and labor market outcomes over the fifty-eight quarter period from 1995 through 2009. Over this period, applicants received disability insurance in $27 \%$ of the quarters, were employed in $38 \%$ of the quarters, and, on average, earned $\$ 1,371$ per quarter. There is interesting variation in these averages across the treatment and impairment groups. For example, the rate of disability insurance receipt varies across the three impairment subgroups, especially SSI receipt which is $9 \%$ for the PI, $16 \%$ for the MI, and 35\% for the CI. Presumably, this reflects the fact that SSI is means-tested and, as observed in Table 1, employment rates and average earnings are highest for clients with physical impairments and lowest for those with cognitive impairments. Finally, treated clients have higher employment rates and average earnings than untreated clients.

Table 1 also provides summary statistics for the demographic variables which include measures of gender, race, education, age, marital status, and number of dependents, as well as measures of transportation availability and participation in Medicaid ${ }^{8}$. Relative to a random sample of US adults, DARS clients are more likely to be black (33\%), less likely to graduate from high school (42\%), less likely to be married (18\%), and less likely to have access to transportation. There are only minor differences in the average characteristics of treated and untreated clients ${ }^{9}$. As might be expected, there are large 
Table 1 Means and standard deviations by treatment status and impairment

\begin{tabular}{|c|c|c|c|c|c|c|c|c|c|c|c|c|}
\hline \multirow[b]{3}{*}{ Variable $^{\text {b }}$} & \multicolumn{6}{|c|}{ Full Sample } & \multicolumn{6}{|c|}{ Impairment $^{\mathrm{a}}$} \\
\hline & \multicolumn{2}{|c|}{ All } & \multicolumn{2}{|c|}{ Treated } & \multicolumn{2}{|c|}{ Untreated } & \multicolumn{2}{|c|}{ PI } & \multicolumn{2}{|c|}{ MI } & \multicolumn{2}{|c|}{$\mathrm{Cl}$} \\
\hline & Mean & $\begin{array}{l}\text { Std } \\
\text { Dev }\end{array}$ & Mean & $\begin{array}{l}\text { Std } \\
\text { Dev }\end{array}$ & Mean & $\begin{array}{l}\text { Std } \\
\text { Dev }\end{array}$ & Mean & $\begin{array}{l}\text { Std } \\
\text { Dev }\end{array}$ & Mean & $\begin{array}{l}\text { Std } \\
\text { Dev }\end{array}$ & Mean & $\begin{array}{l}\text { Std } \\
\text { Dev }\end{array}$ \\
\hline Treat & 0.61 & 0.49 & 1.00 & 0.00 & 0.00 & 0.00 & 0.60 & 0.49 & 0.61 & 0.49 & 0.76 & 0.43 \\
\hline SSDI or SSI ${ }^{b}$ & 0.27 & 0.45 & 0.28 & 0.45 & 0.27 & 0.44 & 0.28 & 0.45 & 0.37 & 0.48 & 0.48 & 0.50 \\
\hline SSI & 0.14 & 0.35 & 0.14 & 0.35 & 0.14 & 0.34 & 0.09 & 0.29 & 0.16 & 0.37 & 0.35 & 0.48 \\
\hline SSDI & 0.17 & 0.38 & 0.17 & 0.38 & 0.17 & 0.37 & 0.22 & 0.41 & 0.26 & 0.44 & 0.21 & 0.41 \\
\hline Employed & 0.38 & 0.49 & 0.40 & 0.49 & 0.35 & 0.48 & 0.40 & 0.49 & 0.35 & 0.48 & 0.32 & 0.47 \\
\hline Earnings & 1371 & 3001 & 1436 & 2712 & 1268 & 3411 & 1608 & 3728 & 1219 & 2586 & 770 & 1786 \\
\hline Age & 31 & 12 & 31 & 12 & 31 & 12 & 39 & 9 & 37 & 9 & 25 & 9 \\
\hline Male & 0.52 & 0.50 & 0.50 & 0.50 & 0.53 & 0.50 & 0.47 & 0.50 & 0.40 & 0.49 & 0.51 & 0.50 \\
\hline White & 0.66 & 0.47 & 0.65 & 0.48 & 0.67 & 0.47 & 0.65 & 0.48 & 0.71 & 0.45 & 0.55 & 0.50 \\
\hline Black & 0.33 & 0.47 & 0.34 & 0.47 & 0.31 & 0.46 & 0.33 & 0.47 & 0.28 & 0.45 & 0.42 & 0.49 \\
\hline Married & 0.18 & 0.39 & 0.17 & 0.37 & 0.21 & 0.41 & 0.37 & 0.48 & 0.18 & 0.38 & 0.04 & 0.19 \\
\hline High school & 0.42 & 0.49 & 0.49 & 0.50 & 0.30 & 0.46 & 0.57 & 0.50 & 0.61 & 0.49 & 0.17 & 0.38 \\
\hline Educ. missing & 0.15 & 0.36 & 0.00 & 0.00 & 0.39 & 0.49 & 0.17 & 0.38 & 0.14 & 0.35 & 0.05 & 0.22 \\
\hline Special educ & 0.09 & 0.28 & 0.12 & 0.32 & 0.04 & 0.20 & 0.02 & 0.12 & 0.02 & 0.14 & 0.33 & 0.47 \\
\hline Family size & 2.8 & 1.6 & 2.8 & 1.6 & 2.7 & 1.6 & 2.4 & 1.4 & 2.1 & 1.5 & 3.2 & 1.8 \\
\hline \# Dependents & 0.66 & 1.12 & 0.61 & 1.08 & 0.74 & 1.18 & 1.08 & 1.27 & 0.84 & 1.19 & 0.37 & 0.93 \\
\hline Transportation & 0.71 & 0.45 & 0.71 & 0.46 & 0.73 & 0.44 & 0.82 & 0.38 & 0.74 & 0.44 & 0.46 & 0.50 \\
\hline Driver's license & 0.60 & 0.49 & 0.59 & 0.49 & 0.61 & 0.49 & 0.79 & 0.41 & 0.68 & 0.46 & 0.17 & 0.38 \\
\hline Medicaid & 0.17 & 0.37 & 0.16 & 0.37 & 0.18 & 0.38 & 0.14 & 0.35 & 0.18 & 0.39 & 0.29 & 0.45 \\
\hline $\mathrm{PI}$ & 0.33 & 0.47 & 0.32 & 0.47 & 0.33 & 0.47 & 1.00 & 0.00 & 0.19 & 0.39 & 0.06 & 0.23 \\
\hline Ml & 0.22 & 0.41 & 0.22 & 0.41 & 0.22 & 0.41 & 0.13 & 0.33 & 1.00 & 0.00 & 0.11 & 0.31 \\
\hline $\mathrm{Cl}$ & 0.15 & 0.35 & 0.18 & 0.39 & 0.09 & 0.29 & 0.03 & 0.16 & 0.07 & 0.26 & 1.00 & 0.00 \\
\hline N & 6732 & & 4139 & & 2593 & & 2192 & & 1479 & & 992 & \\
\hline
\end{tabular}

Note:

a. The impairment groups are not mutually exclusive or exhaustive. For example, there is no separate group for clients with learning disabilities.

Also, for the subgroup analysis, the PI and MI subsamples are restricted to clients age 21 and older. The $\mathrm{Cl}$ sample includes clients 17 and older.

b. Moments for the disability insurance receipt and labor market variables are based on all person-quarters in samples. Moments for the demographic and impairment variables are based on information available in the application quarter.

differences in the observed characteristics across the three impairment groups. For example, the high school graduation rate for the cognitively impaired subgroup is $17 \%$, while the rates for the physically and mentally impaired subgroups are around $60 \%$.

\section{Variation in SSDI/SSI receipt over time}

Figures $1 \mathrm{~A}-\mathrm{C}$ display the quarterly disability insurance receipt rates measured relative to the VR application date. Thus, period 0 is the quarter of application in SFY 2000, period -4 is one year prior to application, and period 4 is one year post-application. Figure 1A displays the rates of receipt of SSDI/SSI for all 6,732 cases. The rate of SSDI receipt monotonically increases over this 15 -year period from a low of around $6 \%$ to a high of $26 \%$. In contrast, the SSI receipt rate slowly increases (from around $10 \%$ to $17 \%$ ) prior to the application quarter and then remains stable at around $17 \%$ thereafter. 

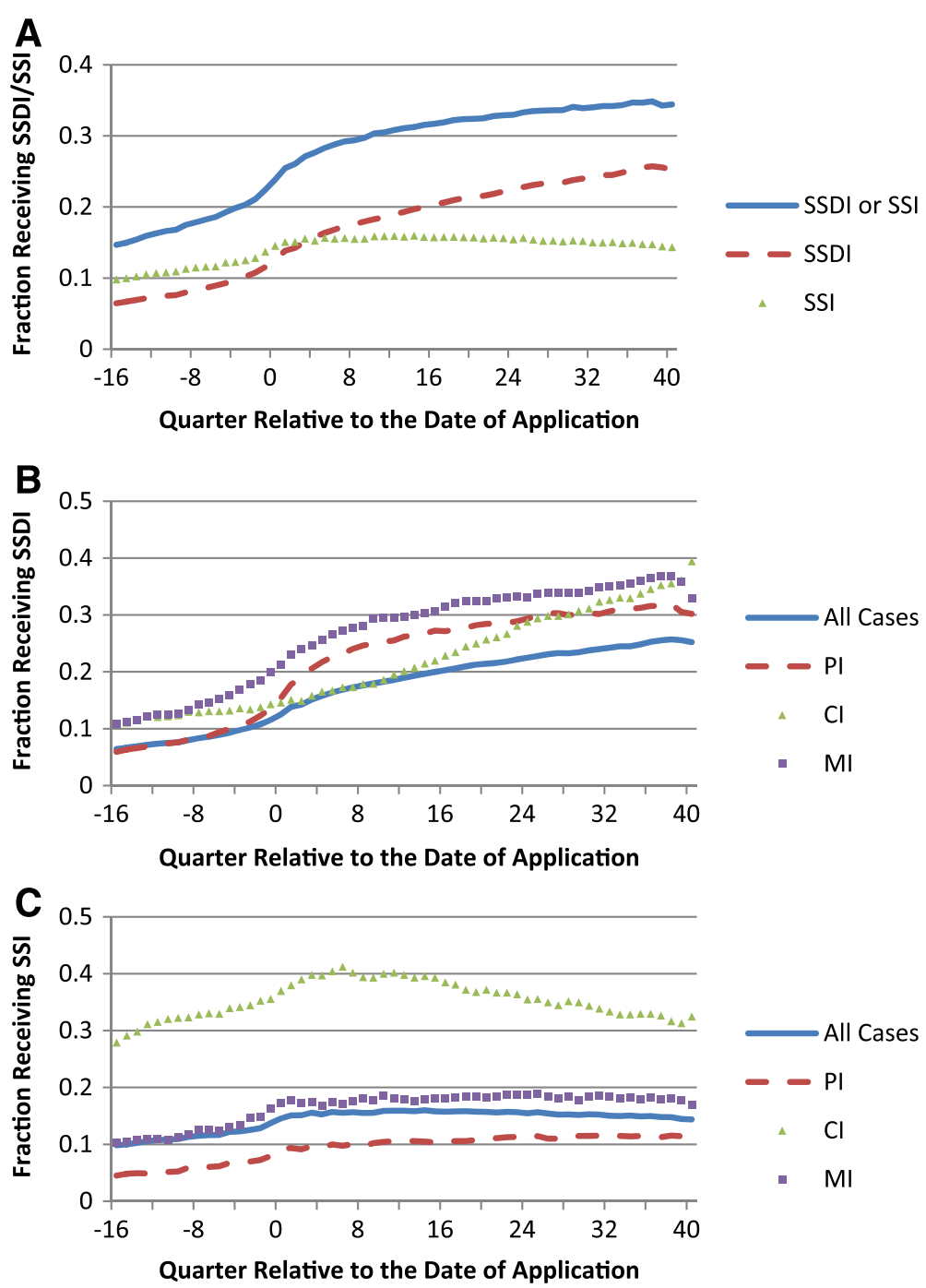

Figure 1 Federal Disability Insurance Receipt Rates by Quarter. (A) SSDI/SSI Receipt Rates. (B) SSDI Receipt Rates by Impairment. (C) SSI Receipt Rate by Impairment.

Figure 1B displays the SSDI receipt rates by impairment group, and Figure $1 \mathrm{C}$ provides the analogous information for SSI receipt. While the rate of SSDI receipt monotonically increases over time for the three impairment groups examined in this study, the patterns of change differ. For those with cognitive impairments, the SSDI receipt rate barely changes prior to the VR application, after which the rate increases rather quickly. For those with mental and physical impairments, the rates of SSDI receipt increase steadily over time except for a sharp discrete jump in the SSDI utilization rate for the PI subsample beginning in quarter zero, the VR application quarter. The sharp jump in the SSDI rate among the physically impaired subgroup is consistent with the sudden and unexpected onset associated with some physical impairments ${ }^{10}$. Workers who suddenly suffer serious physical impairments, for example, may become jointly eligible for VR and SSDI.

The time series patterns of SSI receipt are different (see Figure 1C) in part reflecting the differences in the nonmedical eligibility criteria between the two programs; for the most part, SSDI requires significant work history, while SSI is means-tested. For the MI and PI 
subgroups, the rates of SSI receipt increase slightly until the application period and basically remain fixed thereafter. Notably, there is no discrete jump in participation rates in the period of application. For the cognitively impaired group, the rates increase from about $30 \%$ in quarter -16 to $40 \%$ in quarter 8 , and then steadily fall to around $30 \%$ in quarter 40 . The cognitively impaired are much more likely to be on SSI than other groups of applicants.

\section{Earnings and SSDI/SSI receipt}

In this section, we provide basic descriptive statistics on the association between earnings and SSDI/SSI receipt. Eligibility for SSDI/SSI benefits requires a person must be unable to engage in substantial gainful activity (SGA), defined as earnings at least $\$ 700$ per month in 2000 and at least $\$ 980$ in 2009. SSDI beneficiaries lose their benefits if they engage in SGA for extended periods ${ }^{11}$.

Table 2 displays the distribution of the person-quarters by earnings and SSDI/SSI receipt status $^{12}$. Perhaps what is most striking is the large fraction of observed person-quarters with no earnings; $62 \%$ have zero quarterly earnings and, for those receiving disability insurance (either SSDI or SSI), this "unemployment" rate is $84 \%$. The vast majority of SSDI/SSI recipients who apply for VR services are not employed. Table 2 also reveals striking differences in the earnings patterns by SSDI/SSI participation status. As should be the case, those receiving SSDI/SSI are very unlikely to earn in excess of the SGA threshold. By contrast, a relatively large fraction of those not receiving disability insurance earn in excess of this threshold. Finally, these patterns are common across the impairment groups.

To further explore the relationship between earnings and SSDI/SSI receipt, Figure 2 displays the distribution of person-quarters by the difference in quarterly earnings and the appropriate quarterly SGA level. To focus on the key earnings levels, we restrict the sample person with positive quarterly earnings $(>\$ 100)$ that lie between $[-\$ 2000,+\$ 2000]$ of the quarterly SGA threshold. Figure 2A displays the results by SSDI receipt status and Figure $2 \mathrm{~B}$ by SSI receipt status. Two distinct patterns are revealed in these figures. First, among non-SSDI/SSI recipients, earnings are evenly distributed relative to the SGA level. That is, earnings are not sensitive to the SGA threshold. Second, among SSDI/SSI recipients, the fraction of person-quarters decreases with earnings ${ }^{13}$.

Table 2 Earnings relative to SGA by SSDI/SSI receipt

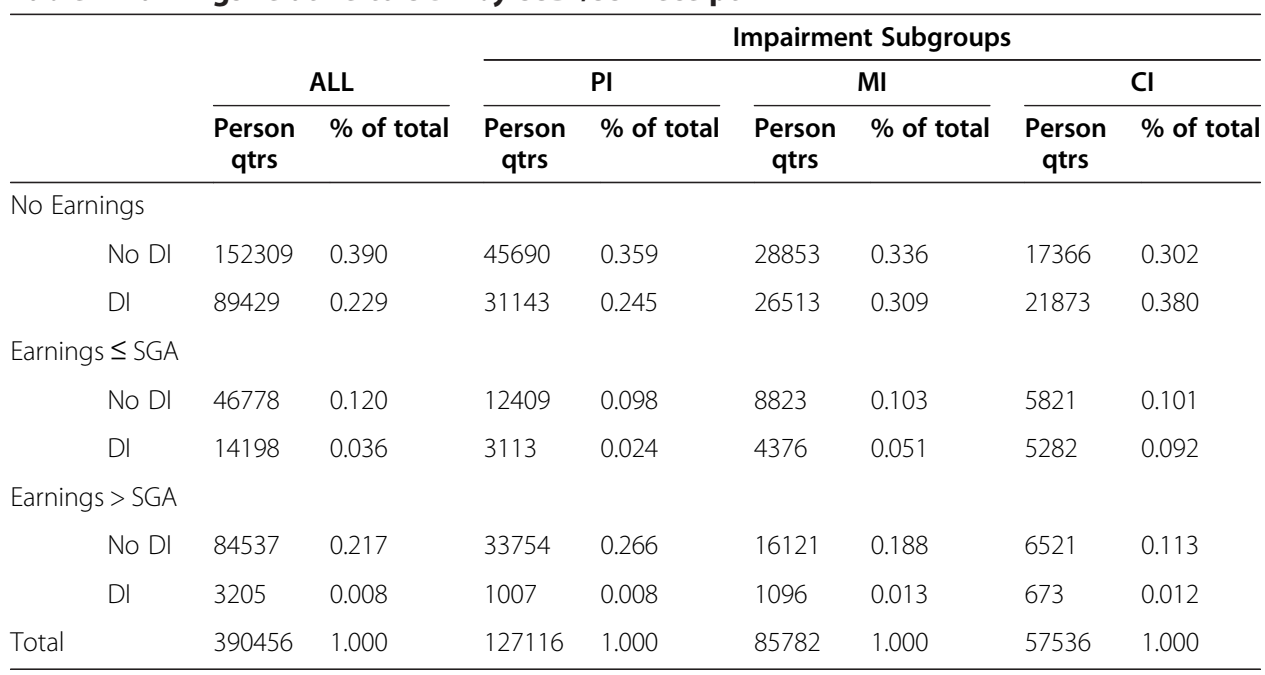

Note: SGA is the quarterly substantial gainful activity level determined by the SSA. 


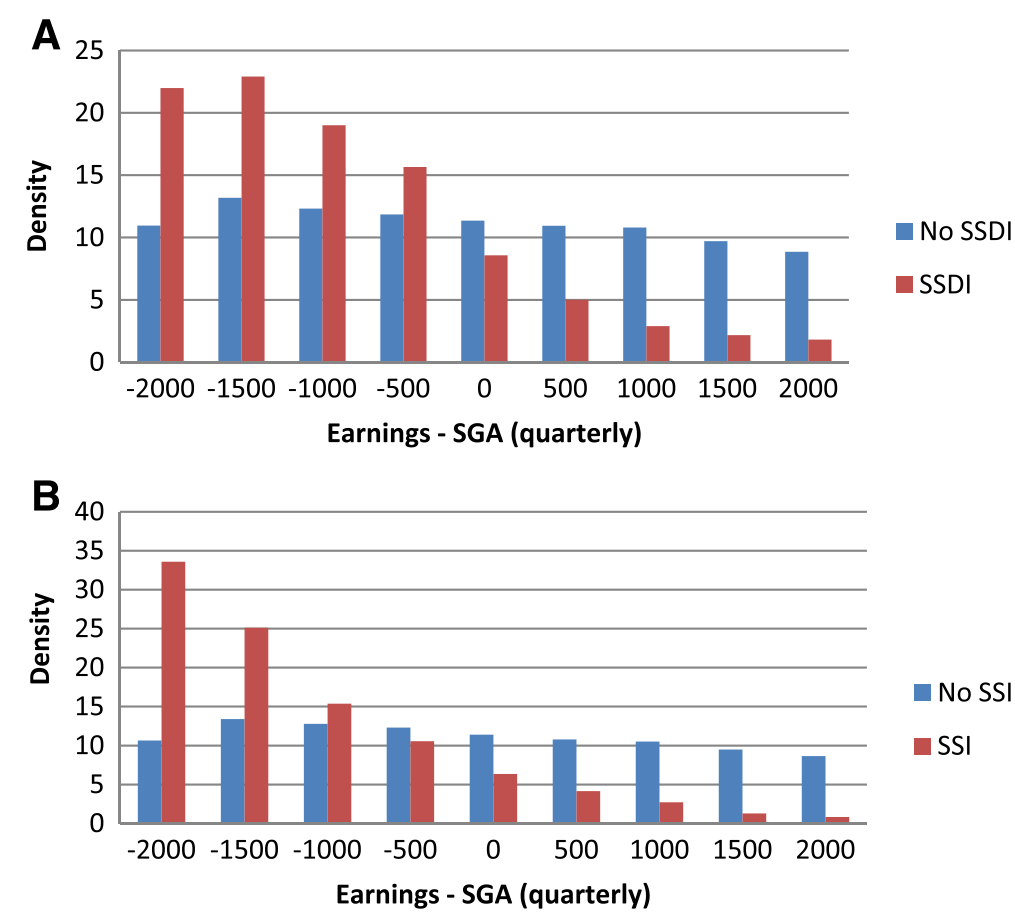

Figure 2 Distribution of VR Applicants (person-quarters) by Earnings - SGA. (A) SSDI Recipients and Non-Recipients. (B) SSI Recipients and Non-Recipients.

Some have suggested that many SSDI recipients might strategically earn just up to the SGA threshold in order to maximize earnings without losing benefits (e.g., GAO General Accountability Office 2002 and Schimmel et al. 2011), a behavioral phenomena referred to as "parking." If true, one might expect the distribution of SSDI recipients to spike upwards when earnings approach the SGA thresholds. For VR applicants, however, we find no evidence that SSDI recipients are parking. In fact, there is little evidence of substantial parking in the general population of SSDI/SSI recipients (GAO General Accountability Office 2002; Schimmel et al. 2011).

\section{VR services and SSDI/SSI receipt}

There is ongoing interest in whether VR programs might reduce the number of persons receiving disability benefits (e.g., see Hennessey and Muller 1995; Autor and Duggan 2010; Stapleton and Martin 2012; Sosulski et al. 2012; Dean et al. 2013a). In this section, we examine the relationship between VR and SSDI/SSI receipt. We begin by displaying the time series patterns of SSDI/SSI receipt by VR treatment status and then report results from a number of different linear regressions that allow us to formally account for preapplication factors as well as the observed covariates listed in Table 1. Finally, we extend the analysis to focus on whether VR services might be associated with SSDI/SSI entry or exit.

\section{VR treatment and SSDI/SSI receipt}

Figures 3, 4 and 5 display the time series patterns of quarterly SSDI/SSI receipt rates by VR treatment status where quarters are measured relative to the application date in SFY 2000. Figure 3 displays the time series of SSDI or SSI receipt, Figure 4 focuses on 


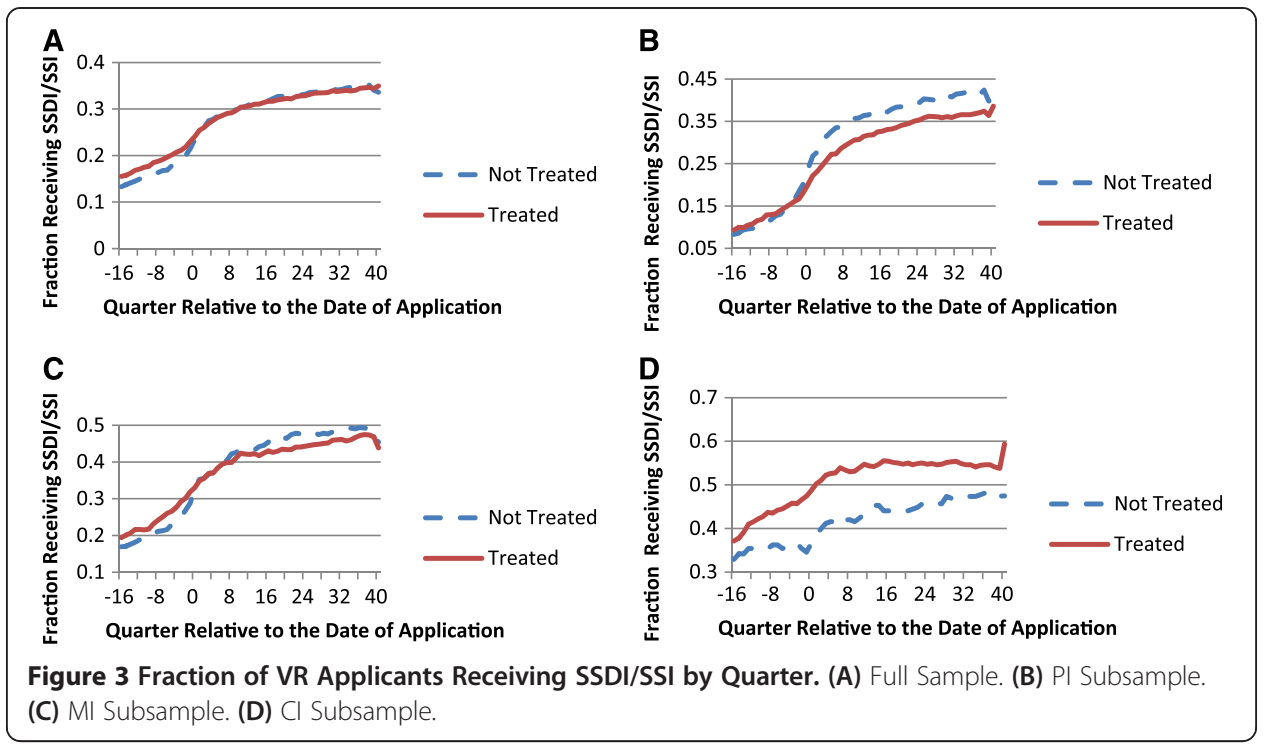

SSDI receipt alone, and Figure 5 focuses on SSI receipt. Each figure has four panels: one for the full sample and one for each of the three impairment groups identified in this analysis (PI, MI, and CI).

A few general patterns are observed in these figures. First, for the full sample as well as the MI and PI subsamples, disability insurance participation rates for the treatment group increase at a slower rate than in the control group. Consider, for example, the results for the physically impaired subsample displayed in Figure 3B. One year prior to the application quarter, the SSDI/SSI receipt rates equal 15\% for both the treated and untreated. One year after the application, the SSDI/SSI rate is $26 \%$ for the treated group and $32 \%$ for untreated. This six point difference between the treated and untreated lasts for nearly ten years. Thus, in this case, VR services appear to be negatively associated with SSDI/SSI receipt. Second, for the cognitively impaired subgroup, these patterns are reversed; SSDI/SSI receipt increases at a slightly faster rate for the treated,

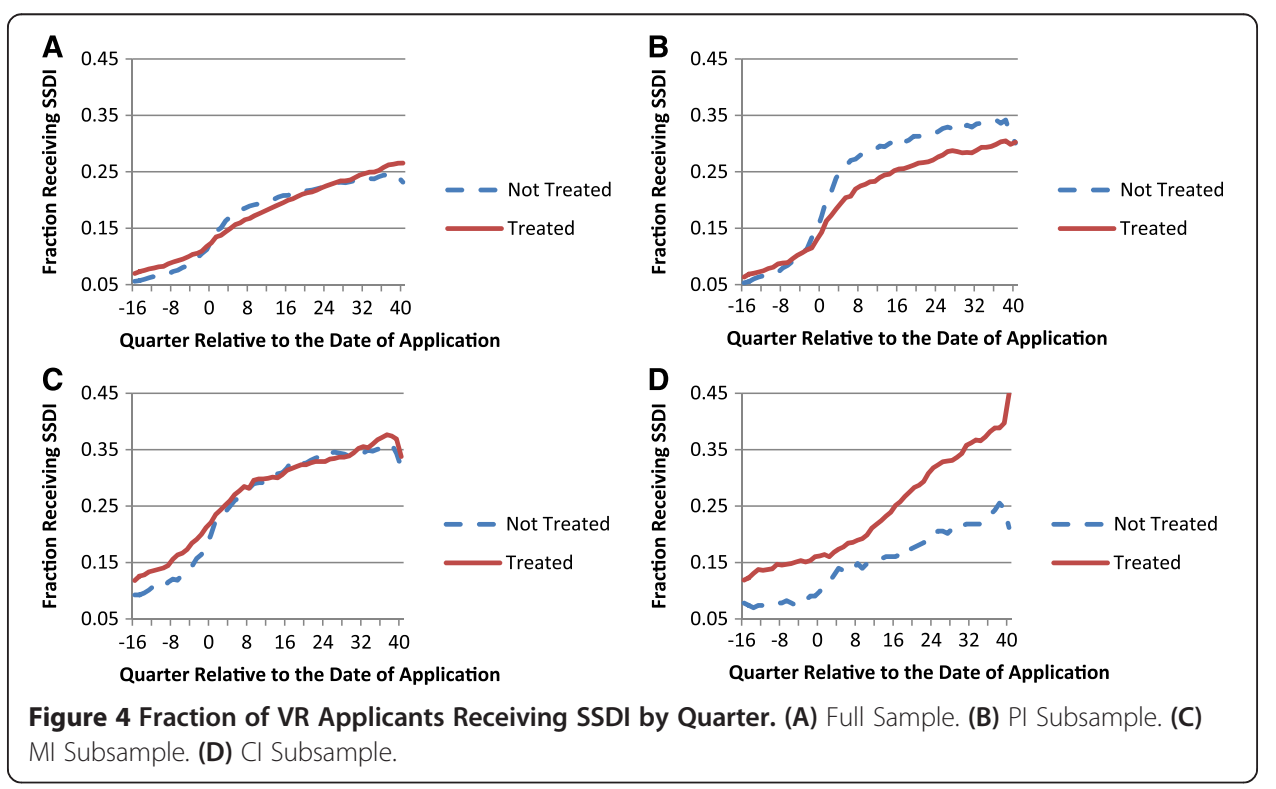




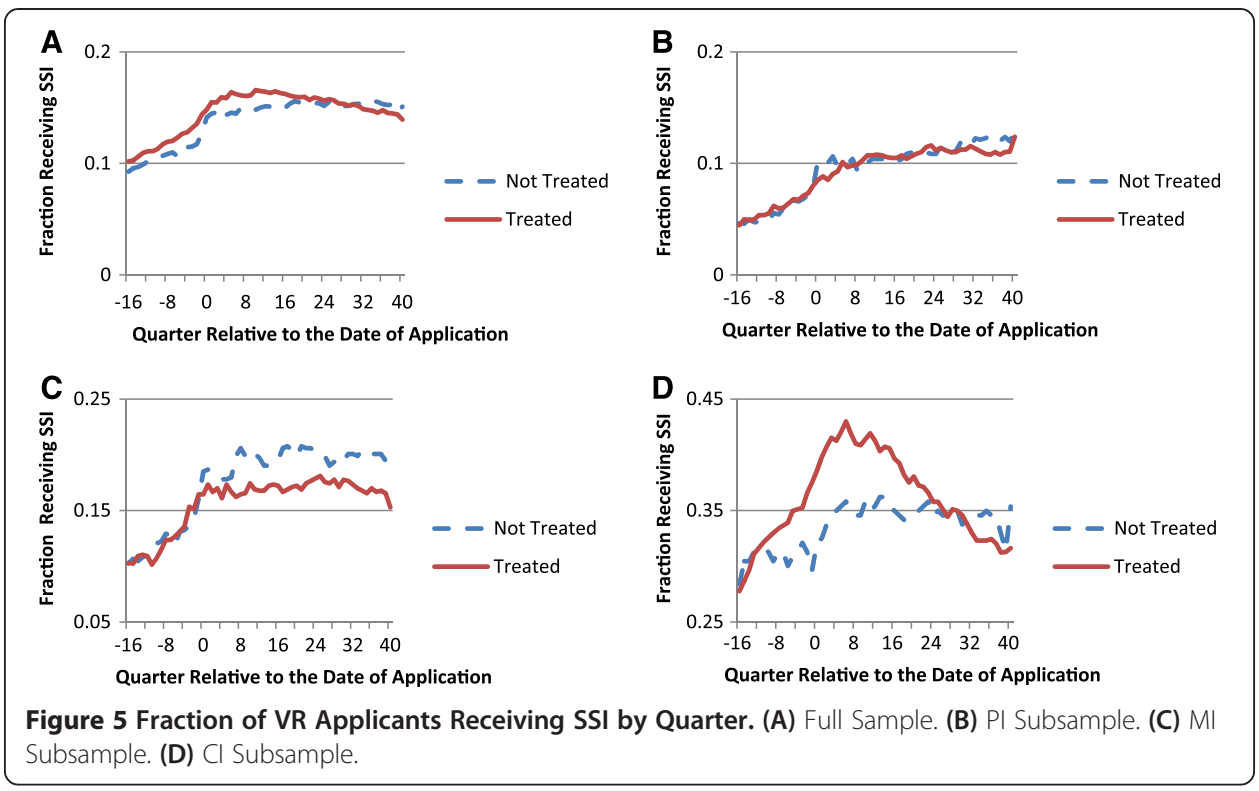

suggesting a positive association between VR and SSDI/SSI receipt. Finally, the time series patterns are somewhat more complex when examining SSI receipt alone (see Figure 5). For the full sample as well as the MI and CI subsamples, SSI receipt rates for the treated increase until about eight quarters post-application, and then consistently fall over the remaining periods. For the PI subsample, SSI receipt rates monotonically increase at about the same rate in the treatment and control groups.

\section{Regression analysis of SSDI/SSI receipt on VR services}

A linear regression model allows us to more systematically explore the association between VR and SSDI/SSI receipt rates by controlling for pre-application SSDI/SSI receipt as well as the covariates listed in Table 1.

Table 3 displays the results from a series of linear regressions of SSDI/SSI receipt on the VR treatment status indicator with and without covariates. The first columns display coefficient estimates and the estimated standard errors from a regression on the postapplication quarters; this model does not use the pre-application information. For all DARS clients, the regression estimates imply a small negative association between SSDI/ SSI receipt and VR services, but these results masks meaningful heterogeneity across impairment groups and disability insurance programs. The physically impaired subsample, for example, has a large negative association $(-0.090)$ between SSDI receipt and VR but a much smaller and statistically insignificant $(-0.002)$ association with SSI receipt. For the MI subsample, there is a small and statistically insignificant association between VR and SSDI receipt yet a large negative association $(-0.032)$ for SSI receipt. Finally, for the cognitively impaired subsample, there is a large positive association between SSDI receipt and VR services and a smaller negative association for SSI receipt. In general, these results suggests VR services are negatively associated with SSDI and SSI receipt for the PI and MI subsamples but positively associated with SSDI for clients with cognitive impairments.

Thus far, the regression models focus on the post-application quarters. To account for the pre-application information on the receipt of SSDI/SSI, we estimate a series of 
Table 3 Regression of SSDI/SSI receipt on VR treatment indicator: VR treatment coefficient estimates and estimated standard errors

\begin{tabular}{|c|c|c|c|c|c|c|}
\hline \multirow[b]{3}{*}{ SSDI or SSI } & \multicolumn{4}{|c|}{ OLS } & \multirow{2}{*}{\multicolumn{2}{|c|}{$\begin{array}{c}\begin{array}{c}\text { Individual \& time fixed-effects } \\
\text { model }\end{array} \\
\text { No covariates }\end{array}$}} \\
\hline & \multicolumn{2}{|c|}{ No covariates } & \multicolumn{2}{|c|}{ Covariate } & & \\
\hline & Coef & SE & Coef & SE & Coef & SE \\
\hline All & $-0.003^{* *}$ & 0.002 & $-0.026^{*}$ & 0.002 & $-0.025^{*}$ & 0.002 \\
\hline $\mathrm{Pl}$ & $-0.047^{*}$ & 0.003 & $-0.093^{*}$ & 0.004 & $-0.052^{*}$ & 0.003 \\
\hline $\mathrm{Ml}$ & $-0.021^{*}$ & 0.004 & $-0.032^{*}$ & 0.005 & $-0.050^{*}$ & 0.004 \\
\hline $\mathrm{Cl}$ & $0.096^{*}$ & 0.006 & $0.047^{*}$ & 0.006 & $0.019^{*}$ & 0.005 \\
\hline \multicolumn{7}{|l|}{ SSDI } \\
\hline All & $-0.003^{*}$ & 0.002 & $-0.015^{*}$ & 0.002 & $-0.017^{*}$ & 0.002 \\
\hline $\mathrm{PI}$ & $-0.046^{*}$ & 0.003 & $-0.090^{*}$ & 0.004 & $-0.051^{*}$ & 0.003 \\
\hline $\mathrm{Ml}$ & 0.004 & 0.004 & -0.003 & 0.004 & $-0.028^{*}$ & 0.004 \\
\hline $\mathrm{Cl}$ & $0.098^{*}$ & 0.005 & $0.074^{*}$ & 0.005 & $0.034^{*}$ & 0.005 \\
\hline \multicolumn{7}{|l|}{ SSI } \\
\hline All & $0.005^{*}$ & 0.001 & $-0.008^{*}$ & 0.002 & $-0.006^{*}$ & 0.001 \\
\hline $\mathrm{Pl}$ & -0.003 & 0.002 & -0.002 & 0.002 & $-0.005^{*}$ & 0.002 \\
\hline $\mathrm{Ml}$ & $-0.026^{*}$ & 0.003 & $-0.032^{*}$ & 0.004 & $-0.024^{*}$ & 0.003 \\
\hline $\mathrm{Cl}$ & $0.026^{*}$ & 0.006 & $-0.013^{*}$ & 0.006 & 0.005 & 0.006 \\
\hline
\end{tabular}

Notes: The full sample is comprised of 265,489 quarterly post-applications observations. The covariates are listed in Table 1. $*^{*}=$ statistically significant at the $5 \%$ level; ${ }^{* *}=$ statistically significant at the $10 \%$ level.

individual fixed effect regression models ${ }^{14}$. In particular, we regress SSDI/SSI receipt on an indicator of whether the applicant receives substantial VR services, a flexible quadratic time trend, and individual fixed effects. Time trends are included to account for the fact that SSDI/SSI receipt is known to change over time, in response to aggregate economic fluctuations ${ }^{15}$. The individual fixed effects are incorporated to account for time invariant factors including health status, skills, and motivation. By comparing the differences in SSDI/SSI receipt between the treated and untreated, before and after the application quarter, the fixed-effects regression model provides an elegant way to incorporate information from the pre-application data.

The results are displayed in the last two columns of Table 3. Except for the CI subsample, these estimates imply a negative association between VR receipt and both SSDI and SSI receipt. For example, SSDI receipt rates are estimated to be 5.1 points lower for physically impaired applicants who receive VR services, and 2.8 points lower for mentally impaired applicants. The analogous figures for SSI receipt are 0.5 and 2.4 points lower, respectively. For cognitively impaired applicants, VR services are estimated to be positively associated with SSDI receipt (3.4 points higher and significant) and SSI receipt (0.5 but insignificant). This might happen if, for the subgroup of applicants with cognitive impairments, VR services have little impact on the labor market but provide clients with basic information about accessing and utilizing the federal disability insurance system.

Finally, to assess whether the estimated relationships vary with time, we estimate these individual fixed-effects regression models restricting the outcome to measure SSDI/SSI receipt at varying quarters post-application. Figure 6 displays the results from five different regressions that restrict the outcome to measures SSDI/SSI receipt one 


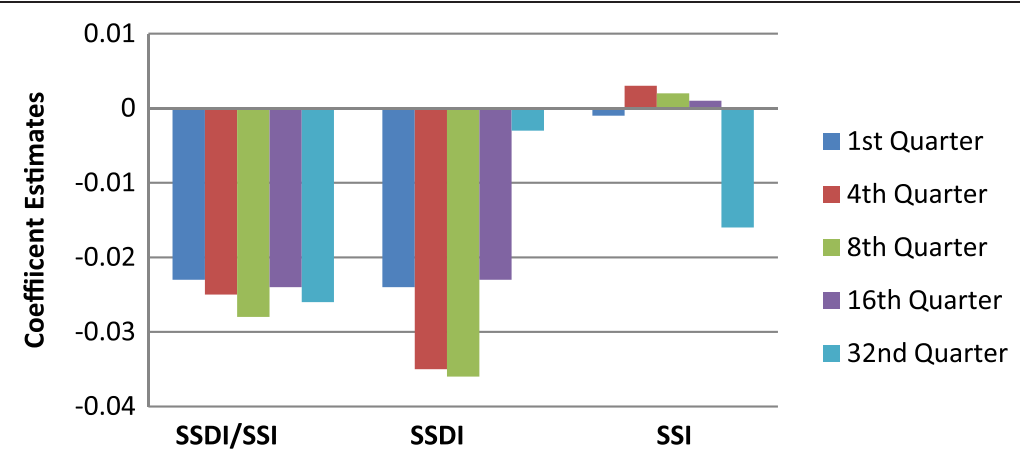

Figure 6 Estimates of the Association between VR and SSDI/SSI by Quarter Post-Application.

quarter, four quarters, eight quarters, sixteen quarters and thirty-two quarters after the VR application in SFY2000. When considering SSDI/SSI receipt together, the estimates are similar across periods, ranging from a low (in absolute value) of around -0.022 to a high of -0.027 . For SSDI receipt, the estimated associations seem to peak at around -0.035 in the first and second year post-application and then drop to almost zero eight years later. In contrast, for SSI, the estimates are negligible for many years post-application and then, by the $32^{\text {nd }}$ quarter, are associated with a relatively large 0.015 reduction in SSI receipt. These results imply fairly stable associations between SSDI/SSI receipt and VR services for many years after VR service receipt. However, eight or more years post-application, there appear to be large changes in the estimated relationships.

Overall, the fixed-effects model results imply that the rates of disability insurance receipt are lower for persons treated by DARS than those untreated. For some cohorts (e.g., clients with physical impairments and mental illness) the estimated coefficients are substantial, suggesting that VR receipt is associated with reductions in SSDI rates in excess of 2 points. In others cases, however, the associations are fairly small and, for the cognitive impairments subgroup, there is a positive association between VR and SSDI/SSI receipt. Thus, while overall the results imply a negative association, we also find a complex and nuanced relationship between VR and disability insurance receipt that varies by program and by impairment group. Moreover, whether these results reveal the casual impact of VR is not certain; the estimated models do not explicitly account for the selection problem. In fact, (Dean et al. 2013a) find that for clients with mental illnesses, VR receipt moderately increases SSDI/SSI receipt rates.

\section{SSDI/SSI entry and exit}

VR assistance may serve to impact disability insurance rolls in two distinct ways. For those receiving disability insurance benefits, VR services may impact the probability of exiting the rolls. For those not receiving federal disability insurance, VR services may impact the probability of applying for and receiving SSDI/SSI. That is, VR may impact the probabilities of exit from and entry into SSDI/SSI.

To explore this idea, we examine the association between VR and SSDI/SSI receipt for those that did and did not receive SSDI/SSI in the four quarters prior to applying for VR services. In the four quarters prior to applying for VR services in SFY 2000, 77\% of the 6,732 applicants had not received any SSDI/SSI benefits, while 19\% received SSDI/SSI 
benefits in all four quarters. Among these two cohorts, the entry and exit rates, respectively, are fairly substantial. Among the respondents not receiving SSDI/SSI benefits prior to SFY 2000, almost 30\% entered the SSDI/SSI rolls within the ten years after applying for VR services. Among the respondents receiving SSDI/SSI benefits prior to SFY2000, nearly $40 \%$ exited SSDI/SSI in the ten years following the VR application.

For each of these two cohorts, Figure 7 displays the time series patterns of quarterly SSDI/SSI receipt rates by VR treatment status, where quarters are measured relative to the application date in SFY 2000. Figure 7A displays the time series for those receiving SSDI/SSI prior to applying for VR service, and Figure 7B displays the analogous rates for those not receiving SSDI/SSI prior to applying for VR services. The net exit rates displayed in Figure 7A are increasing over time (that is, for those receiving payments prior to application, the fraction of SSD/SSI recipients decreases over time), but at a faster rate for the untreated. In contrast, Figure $7 \mathrm{~B}$ shows that the net entry rates among clients not receiving SSDI/SSI prior to the SFY2000 application are lower for the treated than the untreated. Thus, it appears that VR services are associated with lower net entry and net exit rates from SSDI/SSI.

To explore these results in a regression context, we run a series of linear regressions of SSDI/SSI receipt on VR treatment status and covariates, stratified by whether or not the client received SSDI/SSI during the four quarters prior to applying for VR in SFY 2000. The results, which are displayed in Table 4 replicate the basic findings from Figure 7; VR services are associated with a lower probability of exiting and entering SSDI/SSI. For example, for the physically impaired, VR services are associated with a $1.5 \%$ increase in the probability of SSDI/SSI receipt for those who received disability insurance prior to the SFY2000 application and a 9.0\% decrease in the probability

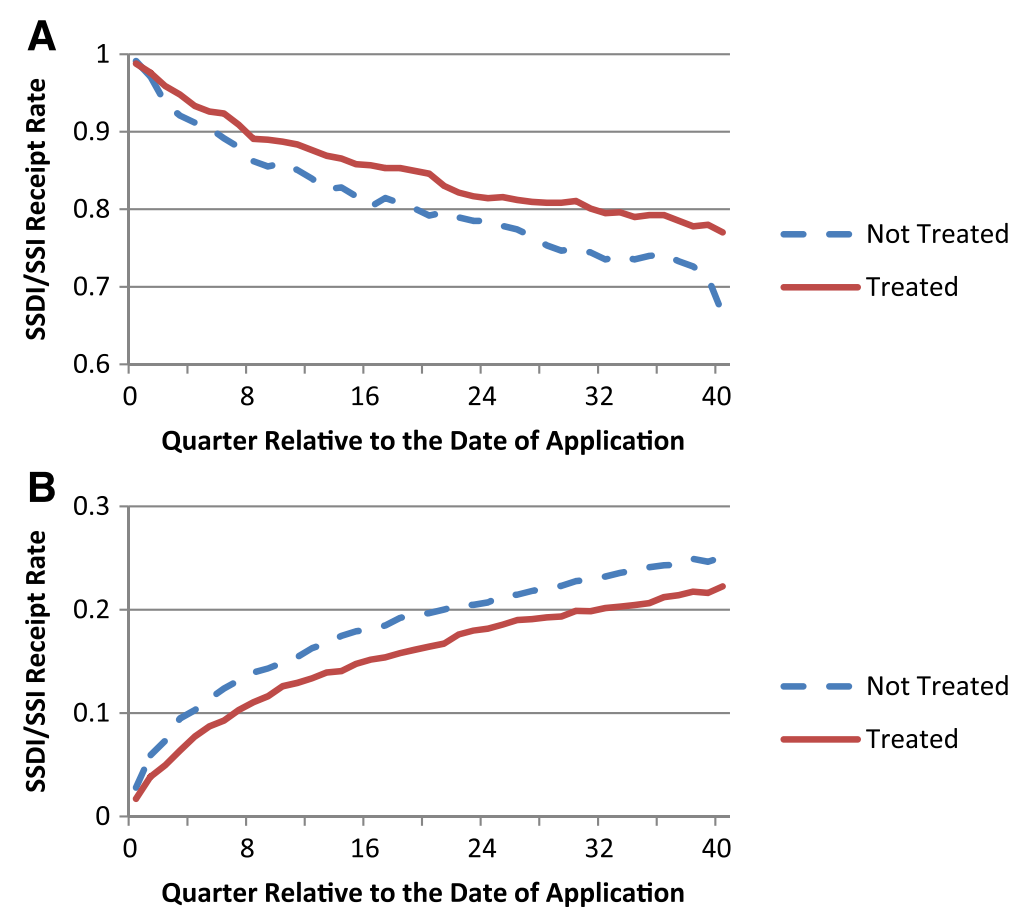

Figure 7 SSDI/SSI Receipt Rate by Quarter. (A) Clients on SSDI/SSI Prior to VR Application. (B) Clients not on SSDI/SSI Prior to VR Application. 
Table 4 Stratified regression of SSDI/SSI receipt on VR treatment indicator and covariates: VR treatment coefficient estimates and estimated standard errors ${ }^{c}$

\begin{tabular}{|c|c|c|c|c|c|}
\hline & & \multicolumn{4}{|c|}{ Pre-Application SSDI/SSI Receipt } \\
\hline & & \multicolumn{2}{|c|}{ Yes $^{\mathrm{a}}$} & \multicolumn{2}{|c|}{$\mathrm{No}^{\mathrm{b}}$} \\
\hline \multirow[t]{5}{*}{ SSDI or SSI } & & Coef & SE & Coef & SE \\
\hline & All & $0.054^{*}$ & 0.004 & $-0.044^{*}$ & 0.002 \\
\hline & $\mathrm{PI}$ & $0.015^{*}$ & 0.008 & $-0.090^{*}$ & 0.004 \\
\hline & $\mathrm{Ml}$ & $0.055^{*}$ & 0.006 & $-0.063^{*}$ & 0.005 \\
\hline & $\mathrm{Cl}$ & $0.050^{*}$ & 0.007 & $-0.038^{*}$ & 0.007 \\
\hline \multirow[t]{5}{*}{ SSDI } & & Coef & SE & Coef & SE \\
\hline & All & $0.108^{*}$ & 0.005 & $-0.037^{*}$ & 0.002 \\
\hline & $\mathrm{PI}$ & $0.025^{*}$ & 0.010 & $-0.086^{*}$ & 0.004 \\
\hline & $\mathrm{Ml}$ & $0.111^{*}$ & 0.009 & $-0.038^{*}$ & 0.004 \\
\hline & $\mathrm{Cl}$ & $0.166^{*}$ & 0.010 & 0.002 & 0.004 \\
\hline \multirow[t]{5}{*}{ SSI } & & Coef & SE & Coef & SE \\
\hline & All & $-0.021^{*}$ & 0.005 & $-0.009^{*}$ & 0.001 \\
\hline & $\mathrm{PI}$ & $0.058^{*}$ & 0.009 & -0.001 & 0.002 \\
\hline & $\mathrm{Ml}$ & $-0.033^{*}$ & 0.009 & $-0.027^{*}$ & 0.003 \\
\hline & $\mathrm{Cl}$ & $-0.098^{*}$ & 0.010 & $-0.042^{*}$ & 0.006 \\
\hline
\end{tabular}

Notes: The regressions are stratified by whether the respondent received or did not receive SSDI/SSI in the year prior to applying for VR services. The coefficient estimates reveal the association between VR and SSDI/SSI receipt. The sample is comprised of 51,155 quarterly post-applications observations for the subsample of cases receiving SSDI/SSI in the year prior to VR application and 208,812 observations in the subsample of cases not receiving SSDI/SSI prior to the VR application. The covariates are listed in Table 1.

a. Respondents receiving DI in all four quarters prior to the VR application $(N=1,266)$.

b. Respondents not receiving $D I$ in any of the four quarters prior to the VR application $(N=5,163)$.

c. The regressions include the covariates listed in Table 1.

* = statistically significant at the $5 \%$ level.

for those who did not receive disability insurance prior to the VR application quarter.

These basic qualitative findings are replicated when examining SSDI alone. By contrast, we find that for SSI receipt the probability of exiting appears to be positively associated with VR services. That is, among applicants who receive SSDI/SSI prior to quarter 0, the rates of post-application SSI receipt are lower for the treated. For example, among the cognitively impaired subgroup, VR services are associated with a 9.8\% drop in the rate of SSI receipt for those who received SSDI/SSI prior the application quarter. Thus, VR services have a mixed association with SSDI receipt but appear to be consistently associated with lower rates of SSI receipt (i.e., reduced entry and increased exits).

\section{VR and employment for SSDI/SSI recipients}

The charge to VR programs is to help disabled individuals stay employed, return to work, or begin new employment. Although a side benefit might be to reduce SSDI/SSI rolls, VR programs have no explicit charge to do so. In this section, we explore whether VR programs are associated with higher employment and earnings for clients who are receiving SSDI/SSI.

Figures 8 and 9 display quarterly employment rates and earnings by the VR treatment status, where quarters are measured relative to application date. Panel A displays the 

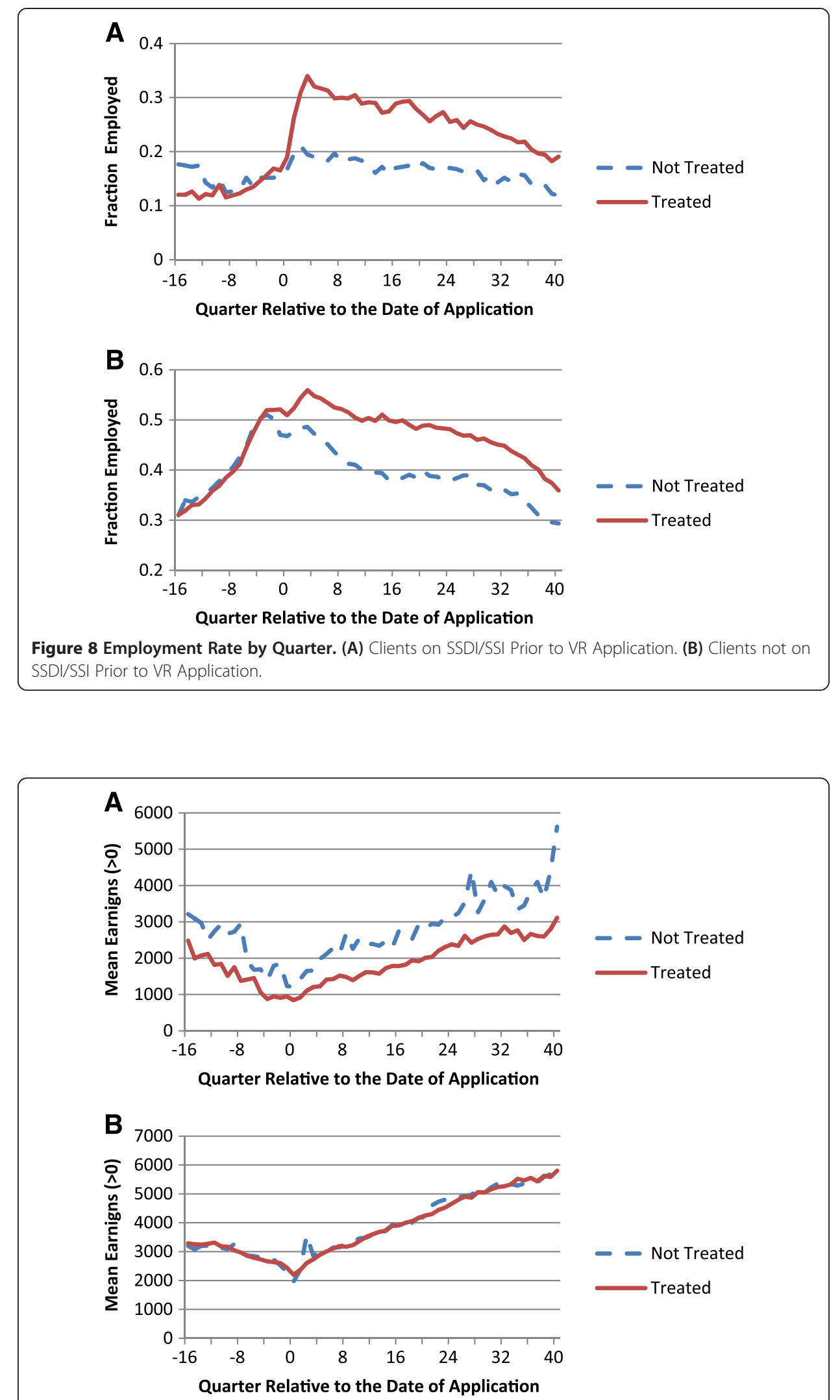

Figure 9 Average Earnings for the Employed by Quarter. (A) Clients on SSDI/SSI Prior to VR Application. (B) Clients not on SSDI/SSI Prior to VR Application. 
labor market time series for clients receiving SSDI/SSI benefits in all four quarters prior to the application date. Panel B displays the time series for clients who did not receive SSDI/SSI benefits in the year before applying for VR services.

Perhaps the most striking finding is that, prior to the application quarter, employment rates of the treated and untreated are nearly identical, while, just afterwards, the treated experience a pronounced increase in employment rates. This spike is especially striking for clients who received SSDI/SSI in the quarters prior to applying for VR services. For example, among applicants receiving SSDI/SSI, the employment rates are 0.15 for both the untreated and treated one year prior to the application quarter. One year after the application, the analogous employment rates are 0.19 for the untreated and 0.32 for the treated. About one year after the application, the employment rates for both the treated and untreated start to decline but a gap between the treated and untreated remains nearly fixed for a decade. After ten years, the employment rates are 0.12 for the untreated and 0.19 for the treated.

Figure 9 displays the time series in earnings among the employed. This figure shows that trends in earnings among the employed are almost identical for both the treated and the untreated throughout.

The basic results shown in Figures 8 and 9 are further explored using a fixed-effects regression model of labor market outcomes (i.e., employment or earnings) on the VR treatment indicator. Table 5 displays the coefficient estimates and standard errors of the VR treatment for a regression on the full sample as well as on the three impairment subsamples. For clients receiving SSDI/SSI prior to applying for services, VR is associated with a $11.7 \%$ increase in the employment rate ${ }^{16}$. For clients not receiving SSDI/ SSI, employment rates are 9.0 points higher for VR beneficiaries. While employment rates are positively associated with VR services, earnings among the employed are notably lower (about $\$ 650$ per quarter) among SSDI/SSI recipients. In summary, we find that, for those receiving SSDI/SSI, VR services are associated with a sharp, substantial, and sustained increase in employment but a drop in mean earnings among the employed.

Table 5 Individual fixed-effect regression estimates of VR on employment and earnings $(>0)$ by Pre-VR application SSDI/SSI receipt status ${ }^{c}$

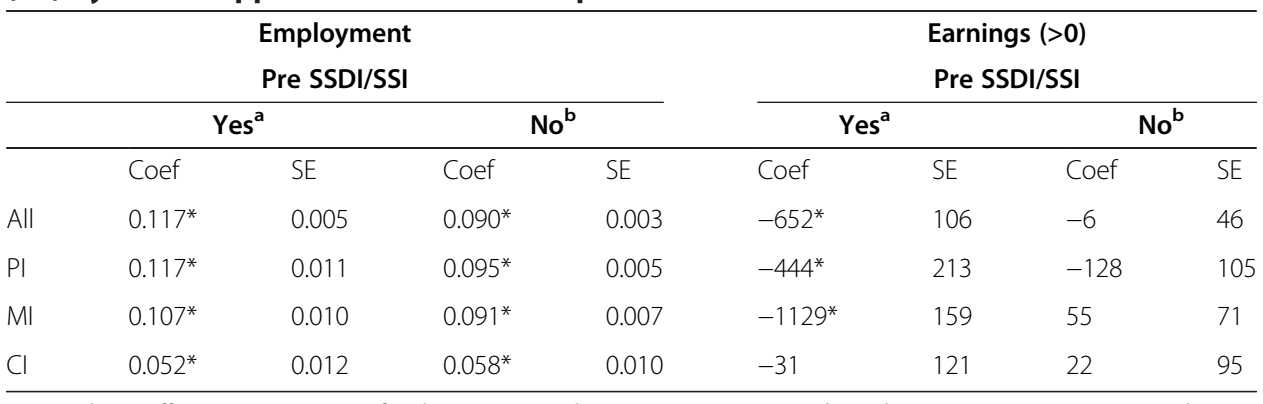

Notes: The coefficient estimates are for the association between VR services and employment or earnings among the employed. The regressions are stratified by whether the applicant received SSDI/SSI in the year prior to applying for VR services.

a. Respondents receiving SSDI in all four quarters prior to the VR application $(N=1,266)$.

b. Respondents not receiving SSDI in any of the four quarters prior to the VR application $(\mathrm{N}=5,163)$.

c. The regressions include the covariates listed in Table 1.

* = statistically significant at the $5 \%$ level.

Note: These coefficients are estimated using the individual fixed-effects regression model. 


\section{Conclusion}

In this paper, we use a unique panel data set of SFY 2000 applicants to the Virginia VR program to explore the relationship between VR services and participation in the two primary Federal Disability Insurance programs, SSDI and SSI. For the most part, we find compelling and consistent evidence that VR receipt is negatively associated with SSDI and SSI receipt, a result that holds for the full population of VR clients as well as subgroups of people with physical and mental impairments. For those with cognitive impairments, however, VR is positively associated with SSDI/SSI receipt. Interestingly, we find that VR is negatively associated with both entry and exit from SSDI. Thus, for clients already receiving disability insurance, VR is associated with a reduced likelihood of leaving the insurance roles, while for clients not receiving SSDI/SSI, VR appears to reduce the chances of taking up SSDI benefits. For SSI, VR appears to be associated with increased exits and reduced entry. Finally, we find that VR services are associated with higher employment rates but somewhat lower average earnings among the employed.

As noted above, we caution against using these results to draw causal conclusions about the impact of VR on SSDI/SSI participation. Although we use some basic regression techniques to control for observable covariates and fixed effects, these results should be interpreted as descriptive in nature. A more sophisticated modeling of the selection problem comprises on-going and future research (see Dean et al. 2013a, 2013b, and 2013c).

Still, the results in this paper provide an important first step in analyzing the data. The estimated associations suggest that VR may play a role in reducing SSDI/SSI receipt. At the same time, we see that the underlying relationships are likely to be nuanced and complex, varying across different disability insurance programs, types of VR services provided, and characteristics of the VR applicants.

\section{Endnotes}

${ }^{1}$ There are a handful of studies assessing the correlation between VR services and SSDI/SSI receipt (e.g., Hennessey and Scott Muller 1995; Tremblay et al. 2006; Rogers et al. 2005; Stapleton and Martin 2012 and Stapleton and Erickson 2004). These studies, which for the most part do not address the selection problem, tend to find that SSDI/SSI receipt is negatively associated with VR. More recently, Dean et al. (2013a) examined SSDI/SSI receipt in a structural model of VR service provision, employment probability, log earnings if employed, and SSI/DI receipt for individuals with mental illness. They find that VR service provision moderately increased SSDI/SSI receipt.

${ }^{2}$ For our analysis, the cognitive impairment subsample only includes clients with diagnosed intellectual disabilities. Those with a learning disability or autism spectrum disorders are not included in the subsample unless they are also classified as having an intellectual disability.

${ }^{3}$ In total, there were 10,322 applicants in SFY2000. To avoid biases associated with left censoring (e.g., Heckman and Singer 1984) we drop observations where the individual's first service spell was prior to SFY 2000 (2782 observations). We also exclude applicants younger than 17 years (433 observations) or older than 55 years 
(375 observations) at time of application as well as those who died while in the program.

${ }^{4}$ There are number of reasons applicants are labeled by the DARS as untreated. Some withdraw their application; others are found to be ineligible for VR services because their disabilities are too severe or not severe enough; and some eligible applicants drop out of the program before substantial services are provided.

${ }^{5}$ The limitations groupings are based on the primary or secondary diagnosis listed in the DARS administrative records when the individual has an open case; this may be the first case in 2000, or it may be a subsequent case. These three categories are not exclusive or exhaustive. The PI and MI subsamples are restricted to clients age 21 or over at the time of application. Additional details on these subsamples are provided by (Dean et al. 2013a, 2013b and 2013c).

${ }^{6} \mathrm{VEC}$ records do not cover all employment, for example, it does not include persons who were self-employed, worked out of state, were federal employers, or worked at contingent-type jobs that do not provide benefits. A comparison by the authors of reported earnings to VEC versus the SSA indicates that about twelve percent of individuals in this cohort show earnings in SSA but not VEC in 2001. (see Dean et al. 2013a, for further details).

${ }^{7} \mathrm{~A}$ Memorandum of Agreement between the SSA and the Virginia DARS allowed us to obtain monthly SSI and SSDI payments for individuals in our sample through a procedure that prevents us from identifying individuals in the sample.

${ }^{8}$ Education information is missing for $15.0 \%$ of the sample. Rather than exclude such observations, we code the high school graduation and special education indicators as zero and included a dummy variable for when education information.

${ }^{9}$ The large differences in the rates of high school graduation and receipt of special education are highly influenced by the treatment of the cases with missing education information. This will be accounted for in the regression models by using the indicator for whether education is missing.

${ }^{10}$ Dean et al. 2013c, discuss and illustrate the importance of modeling this feature of physical impairments in models of VR take-up.

${ }^{11}$ Some SSDI beneficiaries are allowed to engage in SGA for limited periods without benefit loss (see Stapleton and Martin (2012) for details). SSI benefits are based on a basic negative income tax formula where, after a modest earnings disregard, each additional dollar in earnings reduces benefits by fifty cents.

${ }^{12}$ The qualitative findings are similar when SSDI and SSI receipt are disaggregated.

${ }^{13}$ These general patterns are replicated across the three impairment subgroups as well as for other subgroups of VR applicants (e.g., new SSDI beneficiaries).

${ }^{14}$ In particular, we estimate the following mean regression model:

$$
\mathrm{E}[\mathrm{Y} \mid \mathrm{T}, \mathrm{X}]=\alpha_{\mathrm{i}}+\theta \mathrm{T}+\mathrm{f}\left(\text { quarter, } \alpha_{\mathrm{q}}\right)
$$

where $\mathrm{Y}$ is an indicator for SSDI/SSI receipt, $\alpha_{\mathrm{i}}$ is the unknown vector of fixed individual effects, $\mathrm{T}$ is an indicator for whether the respondent received substantial VR services, and $\mathrm{f}\left(\right.$ quarter, $\alpha_{\mathrm{q}}$ ) allows the receipt of SSDI/SSI to vary over time (we use a quadratic time trend with an indicator for quarters post VR application). We also estimated similar difference-in-difference models. The results are almost identical to the fixed effects model estimates and thus are not reported in this paper. 
${ }^{15}$ Given that we only observe VR receipt in a single SFY, we cannot evaluate whether the association between VR and SSDI/SSI to varies over time.

${ }^{16}$ While we classify an applicant as employed if they have any quarterly earnings, the results are similar for other earnings thresholds. In particular, when using an indicator for quarterly earnings in excess of $\$ 1500$, the resulting coefficients estimates were somewhat smaller in magnitude but had the same qualitative implications. For example, the estimate associated with the PI cohort receiving SSDI/SSI prior to VR application falls from 0.117 to 0.075 , both significant at the $5 \%$ level.

\section{Competing interest}

The IZA Journal of Labor Policy is committed to the IZA Guiding Principles of Research Integrity. The authors declare that they have observed these principles.

\section{Acknowledgements}

We would like to thank Joe Ashley, John Phelps, Kirsten Rowe, Ann Stanfield, Vlad Mednikov, and Jim Rothrock from Virginia Department of Aging and Rehabilitation Services (DARS), Paul O.Leary of the Social Security Administration, David Stapleton, other members of the National Institute of Disability and Rehabilitation Research (NIDRR) Advisory Group, and Rachel Fowley for excellent research assistance. The DARS, the Virginia Department of Medical Assistive Services, the NIDRR, and the University of Virginia Bankard Fund for Political Economy provided generous financial support. All errors are ours.

This paper was submitted to the IZA Journal of Labor Policy's call for papers on "Social Security Disability Benefits: Finding Alternatives to Benefit Receipt". Two special editors, David Wittenburg and Gina Livermore, were sponsored by the University of New Hampshire's Rehabilitation, Research, and Training Center on Employment Policy and Measurement, funded by the U.S. Department of Education (ED), National Institute on Disability and Rehabilitation Research (cooperative agreement no. H133B100030). Their comments do not necessarily represent the policies of ED or any other federal agency (Edgar, 75.620 (b)). The authors are solely responsible for all views expressed. Responsible editor: David Wittenburg

\section{Author details}

${ }^{1}$ University of Richmond, Richmond, VA, USA. ${ }^{2}$ University of Virginia, Charlottesville, VA, USA.

Received: 14 October 2013 Accepted: 10 February 2014

Published: 08 Apr 2014

\section{References}

Aakvik A, Heckman J, Vytlacil E (2005) Estimating treatment effects for discrete outcomes when responses to treatment vary: an application to Norwegian Vocational Rehabilitation Programs. J Ecometr 125:15-51

Autor D, Duggan M (2010) Supporting Work: A Proposal for Modernizing the U.S. Disability Insurance System. Hamilton Project

Baldwin M (1999) The Effects of Impairments of Employment and Wages: Estimates from the 1984 and 1990 SIPP. Behav Sci Law 17:7-27

Dean D, Dolan R (1991) Fixed-effects estimates of earnings impacts for the vocational rehabilitation program. J Hum Resour 26(2):380-391

Dean D, Dolan R, Schmidt R (1999) Evaluating the vocational rehabilitation program using longitudinal data: evidence for a quasi-experimental research design. Eval Rev 23(2):162-189

Dean D, Pepper J, Schmidt R, Stern S (2013a) The Effects of Vocational Rehabilitation for People with Mental Illness. Unpublished manuscript

Dean D, Pepper J, Schmidt R, Stern S (2013b) The Effects of Vocational Rehabilitation for People with Cognitive Impairments. Unpublished manuscript

Dean D, Pepper J, Schmidt R, Stern S (2013c) The Effects of Vocational Rehabilitation for People with Physical Disabilities. Unpublished manuscript

Friedlander D, Greenberg D, Robins P (1997) Evaluating government training programs for the economically disadvantaged. J Econ Lit 35(4):1809-1855

(GAO) General Accountability Office (2002) SGA Levels Appear to Affect the Work Behavior of Relatively Few Beneficiaries, but More Data Needed, Report to the Committee on Finance, US Senate and the Committee on Ways and Means, House of Representatives, Reports 02-224

Heckman J, Singer B (1984) Econometric duration analysis. J Econ 24:63-132

Hennessey J, Scott Muller L (1995) The effect of vocational rehabilitation and work incentives on helping the disabledworker beneficiary back to work. Soc Secur Bull 58(1):15-28

Imbens G, Wooldridge J (2009) Recent developments in the econometrics of program evaluation. J Econ Lit 47(1):5.86

LaLonde R (1995) The promise of public sector-sponsored training programs. J Econ Perspect 9(2):149-168

Loprest P (2007) Strategic Assessment of the State of the Science in Research on Employment for Individuals with Disabilities, National Institute for Disability and Rehabilitation Research. Contract GS23F8198H

Marcotte D, Wilxox-Gok V, Redmond D (2000) The Labor Market Effects of Mental Illness: The Case of Affective Disorders. In: Salkever D, Sorkin A (eds) The Economics of Disability. JAI Press, Greenwich, CT 
Rogers J, Bishop M, Crystal M (2005) Predicting rehabilitation outcome for supplemental security income and social security disability insurance recipients: implications for consideration with the ticket to work program. J Rehabil 71 (3):5-10

Schimmel J, Stapleton D, Song J (2011) How common is 'Parking' among social security insurance beneficiaries? evidence from the 1999 change in the earnings level of substantial gainful activity. Soc Secur Bull 71(4):77-92

Sosulski M, Donnell C, Kim WJ (2012) Disability and employee benefits receipt: evidence from the U.S. Vocational rehabilitation services program. J Soc Work Disabil Rehabil 11(1):33-54

Stapleton D, Erickson W (2004) Characteristics of Incentives: Why Do Employment Outcomes for the SSA Beneficiary Clients of VR Agencies Differ, on Average, from Those of Other Clients? Cornell University Institute for Policy Research, Washington DC

Stapleton D, Martin F (2012) Vocational Rehabilitation on the Road to Social Security Disability: Longitudinal Statistics from Matched Administrative Data. Unpublished manuscript

Tremblay T, Smith J, Xie H, Drake R (2006) Effect of benefits counseling services on employment outcomes for people with psychiatric disabilities. Psychiatr Serv 57(6):816-821

10.1186/2193-9004-3-7

Cite this article as: Dean et al: State vocational rehabilitation programs and federal disability insurance: an analysis of Virginia's vocational rehabilitation program. IZA Journal of Labor Policy 2014, 3:7

\section{Submit your manuscript to a SpringerOpen ${ }^{\circ}$ journal and benefit from:}

- Convenient online submission

Rigorous peer review

- Immediate publication on acceptance

- Open access: articles freely available online

- High visibility within the field

- Retaining the copyright to your article

Submit your next manuscript at $\gg$ springeropen.com 